\title{
Commute times and audiometric findings among adult population in Mexico City
}

\author{
Cuauhtémoc A. Juárez-Pérez, ${ }^{1}$ Alejandro Cabello-López, ${ }^{\text {* }}$ Guadalupe Aguilar-Madrid, ${ }^{2}$ \\ Óscar Trujillo-Reyes, ${ }^{1}$ Arturo Torres-Valenzuela, ${ }^{3}$ Rosalía Fascinetto-Dorantes, ${ }^{1}$ \\ Carmina Jiménez-Ramírez $z^{4}$ and Åsa Skjönsberg ${ }^{5}$ \\ ${ }^{1}$ Occupational Health Research Unit, Centro Médico Nacional Siglo XXI, Instituto Mexicano del Seguro Social, Mexico City, Mexico; ${ }^{2}$ Department \\ of Public Health, Faculty of Medicine, Universidad Nacional Autónoma de México, Ciudad de México, México, Instituto Mexicano del Seguro Social, \\ Mexico City, Mexico, Instituto Mexicano del Seguro Social, Mexico City, Mexico; ${ }^{3}$ Audiology Department, Centro Médico Nacional Siglo XXI, Instituto \\ Mexicano del Seguro Social, Mexico City, Mexico; ${ }^{4}$ Clinical Analysis Laboratory, Hospital de Traumatología "Dr. Victorio De la Fuente Narváez", \\ Instituto Mexicano del Seguro Social, Mexico City, Mexico; ${ }^{5}$ Department of Clinical Science, Intervention and Technology, Audiology Division, \\ Karolinska Institutet, Huddinge, Sweden
}

\begin{abstract}
Introduction: Long commute times are common in big cities. Objective: To determine hearing thresholds and their association with commute time in Mexico City. Methods: Cross-sectional study that included 177 healthy adults from 2009 to 2011. Demographic information and commute times were recorded. Hearing was assessed by audiometry. Regression models were constructed to determine the predictors of hearing thresholds. Results: There were 101 men (53\%) and 76 women (43\%). Mean commute time was 43 minutes (1-150 minutes). A hearing threshold drop was observed at $4000 \mathrm{~Hz}$, with recovery at $8000 \mathrm{~Hz}$ in both ears when patients were stratified by gender and age groups. A commute time $>40 \mathrm{~min} /$ day increased the hearing threshold at $4000 \mathrm{~Hz}$ $(\beta=2.96 \mathrm{~dB} H \mathrm{HL}, p<0.01)$. Men had higher thresholds $(\beta=2.6 \mathrm{~dB} \mathrm{HL})$, as older subjects also did: $25-34$ years, $\beta=2.2 \mathrm{~dB} H \mathrm{H}$; $35-44$ years, $\beta=5.2 \mathrm{~dB} H \mathrm{H}$; and $\geq 45$ years, $\beta=8.3 \mathrm{~dB}$ HL. Conclusion: The hearing pattern, although normal, resembled that of noise-induced hearing loss, associated with long commute times.
\end{abstract}

KEY WORDS: Transportation. Hearing loss. Environmental exposure. Mexico.

\section{Tiempos de traslado al trabajo y hallazgos auditivos en la población adulta de la Ciudad de México}

\section{Resumen}

Introducción: Los tiempos prolongados de traslado son comunes en las ciudades grandes. Objetivo: Determinar los umbrales auditivos y su asociación con el tiempo de traslado al trabajo en la Ciudad de México. Métodos: Estudio transversal que incluyó a 177 adultos sanos de 2009 a 2011. Se registró información demográfica y tiempo de traslado al trabajo. La audición se evaluó mediante audiometría. Se realizaron modelos de regresión para determinar los predictores de los umbrales auditivos. Resultados: Se trató de 101 hombres (53 \%) y 76 mujeres (43\%). El tiempo promedio de traslado fue 43 minutos (1 a 150 minutos). Se observó una caída del umbral auditivo en $4000 \mathrm{~Hz}$, con recuperación en $8000 \mathrm{~Hz}$ en ambos oídos al estratificar por sexo y grupos de edad. Un tiempo de traslado $>40$ minutos/día incrementó el umbral auditivo en $4000 \mathrm{~Hz}(\beta=2.96 \mathrm{~dB} \mathrm{HL}$, $p<0.01)$. Los hombres presentaron umbrales mayores $(\beta=2.6 \mathrm{~dB} \mathrm{HL})$, al igual que los sujetos de edad más avanzada: 25 a 34 años, $\beta=2.2 \mathrm{~dB} H \mathrm{HL} ; 35$ a 44 años, $\beta=5.2 \mathrm{~dB} H \mathrm{HL} y \geq 45$ años, $\beta=8.3 \mathrm{~dB}$ HL. Conclusión: El patrón auditivo, aunque normal, se asemejó a la pérdida auditiva por ruido asociada a tiempo prolongado de traslado al trabajo.

PALABRAS CLAVE: Transporte. Pérdida auditiva. Exposición ambiental. México.

Correspondence:

*Alejandro Cabello-López

E-mail: alejandrocabellolopez@gmail.com
Gac Med Mex. 2021;157:364-370

Contents available at PubMed

www.gacetamedicademexico.com

0016-3813/@ 2021 Academia Nacional de Medicina de México, A.C.. Published by Permanyer. This is an open access article under the CC BY-NC-ND license (http://creativecommons.org/licenses/by-nc-nd/4.0/). 


\section{Introduction}

Big cities are faced with urban dynamics and their environmental consequences. Among the latter, noise pollution and mobility problems are particularly important in large urban conglomerates such as Mexico City, one of the noisiest cities in Latin America due to traffic congestions ${ }^{1}$.

As a megalopolis, Mexico City has experienced significant population growth since 1970, which has caused urban settlements to expand to the periphery. Parallel to this population growth (nearly 22 million inhabitants by 2020), economic activities have increased, which has led to an increase in the number of commutes within this area, which is partially explained by the proliferation of motor vehicles, which in 1980 accounted for to nearly 1.8 million units, and by 2017 the number increased to 5.4 million $^{2,3}$. As a consequence, Mexico City faces severe mobility problems. According to official reports, commuting times range from 30 minutes to 2 hours due to traffic congestion ${ }^{4}$, which also generates noise levels close to 80 decibels $(\mathrm{dBA})$. On the other hand, the noise generated by the public transport system ( $85 \mathrm{dBA})$, heavy vehicles (100 dBA) and aircrafts (150 dBA) exacerbate this exposure in Mexico City residents ${ }^{5,6}$.

In light of this situation, the question on whether commuting times in Mexico City can affect audiological health of its inhabitants arises, since urban mobility is a challenge in this city and hearing loss is a public health problem -it constitutes the fourth contributor of years lived with disability in Mexico (366 per 100,000 population) ${ }^{7}$. Furthermore, it is important to explore if Mexico City population has normal hearing profiles despite this urban stressor.

The purpose of the research herein presented was to determine hearing thresholds and their association with commute times in a group of healthy adults from Mexico City, grouped by age and gender.

\section{Methods}

A cross-sectional analysis covering the 2009-2011 period was carried out, which included 196 healthy Mexican adults who attended as donors at the Blood Bank of Mexican Institute of Social Security Siglo XXI National Medical Center in Mexico City. The participants had been previously recruited for an investigation that evaluated brainstem auditory evoked potentials with the purpose to use these values as reference in occupational studies ${ }^{8}$.
The study population included males and females aged between 16 and 65 years, who were applied a questionnaire to collect sociodemographic information, including commuting time and occupation. In addition, the participants were asked about the presence of otologic symptoms, use of ototoxic drugs, any ear disease and sequelae thereof, as well as frequent upper respiratory tract infections (more than 5 episodes per year), chronic degenerative diseases (diabetes mellitus, hypertension, and dyslipidemia), and history of head trauma. In addition, occupational exposure to noise and ototoxic substances was considered, along with environmental and recreational noise exposure. In order to assess participants' health status, blood glucose levels, blood pressure, weight and height were measured by trained nursing staff. On the other hand, participants who had a diagnosis or sequelae of any chronic, ear or neurological disease were excluded, as well as those with a history of occupational exposure to noise or industrial ototoxic agents, prolonged use of ototoxic drugs, or sudden changes in barometric pressure. Similarly, people who did not complete the questionnaire, hearing assessment or who decided to withdraw from the study were excluded from analysis.

\section{Audiological evaluation}

An audiologist performed a complete physical examination of the outer ear canal and all hearing tests, which included impedance measurement (tympanometry and ipsilateral stapedial reflex) and audiometry. Pure-tone audiometry was carried out in a sound-proof chamber with a calibrated two-channel audiometer

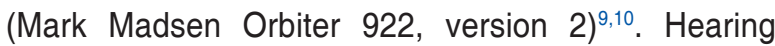
thresholds were obtained in both ears at a frequency range from 125 to $8000 \mathrm{~Hz}$, according to the ascending method modified by Carhart and Jerger, which has been shown to be a valid tool for assessing hearing loss with a specificity of $92 \%$ and sensitivity of $96 \%{ }^{11}$. Participants with hearing thresholds higher than $25 \mathrm{dBA}$ in hearing level $(\mathrm{dB} \mathrm{HL})$ in two or more of the evaluated frequencies were excluded from the analysis, according to the definition of hearing loss proposed by the World Health Organization ${ }^{12}$.

\section{Statistical analysis}

The information was captured in Microsoft Excel 2013. Stata MP 14 was used for statistical analysis, and graphs were created with GraphPad Prism 6. On 
Table 1. Main characteristics of a sample of healthy adults from Mexico City, 2009-2011

\begin{tabular}{|c|c|c|c|c|c|c|}
\hline \multirow[t]{2}{*}{ Variables } & \multicolumn{2}{|c|}{ Total $n=177$} & \multicolumn{2}{|c|}{ Women $n=76$} & \multicolumn{2}{|c|}{ Men $n=101$} \\
\hline & \multicolumn{2}{|c|}{ Mean \pm SD $(\min -\max )$} & \multicolumn{2}{|c|}{ Mean \pm SD $(\min -\max )$} & \multicolumn{2}{|c|}{ Mean \pm SD $(\min -\max )$} \\
\hline Age (years) & \multicolumn{2}{|c|}{$29.7 \pm 9.06(16-61)$} & \multicolumn{2}{|c|}{$30.2 \pm 9.39(17-54)$} & \multicolumn{2}{|c|}{$29.2 \pm 8.82(16-61)$} \\
\hline Travel time to work (min) & \multicolumn{2}{|c|}{$43.6 \pm 30.4(1-150)$} & \multicolumn{2}{|c|}{$40.8 \pm 27.29(5-120)$} & \multicolumn{2}{|c|}{$45.3 \pm 32.24(1-150)$} \\
\hline Body mass index $\left(\mathrm{kg} / \mathrm{m}^{2}\right)$ & \multicolumn{2}{|c|}{$25.6 \pm 3.91(16.3-38)$} & \multicolumn{2}{|c|}{$25.8 \pm 4.13(17.8-36.8)$} & \multicolumn{2}{|c|}{$25.4 \pm 3.75(16.3-38)$} \\
\hline Blood glucose (mg/dL) & \multicolumn{2}{|c|}{$105.9 \pm 28.73(55-235)$} & \multicolumn{2}{|c|}{$102.7 \pm 31.64(55-235)$} & \multicolumn{2}{|c|}{$108.4 \pm 26.21(59-190)$} \\
\hline \multirow[t]{2}{*}{$\begin{array}{l}\text { Blood pressure }(\mathrm{mm} \mathrm{Hg}) \\
\text { Systolic } \\
\text { Diastolic }\end{array}$} & \multicolumn{2}{|c|}{$\begin{array}{c}113.4 \pm 9.06(87-140) \\
72.8 \pm 0.09(57-90)\end{array}$} & \multicolumn{2}{|c|}{$\begin{array}{c}111.4 \pm 9.64(90-132) \\
72 \pm 6.88(60-85)\end{array}$} & \multicolumn{2}{|c|}{$\begin{array}{c}114.9 \pm 8.34(87-140)^{*} \\
73.4 \pm 7.22(57-90)\end{array}$} \\
\hline & $\mathrm{n}$ & $\%$ & $n$ & $\%$ & $\mathrm{n}$ & $\%$ \\
\hline $\begin{array}{l}\text { Type of occupation } \\
\text { Professional } \\
\text { Skilled non-manual } \\
\text { Skilled manual } \\
\text { Family history of deafness } \\
\text { Smoking } \\
\text { Alcohol consumption } \\
\text { Frequent upper respiratory tract infections } \\
\text { Otitis media } \\
\text { Traumatic brain injury } \\
\text { Use of ototoxic drugs } \\
\text { Vertigo } \\
\text { Ear fullness } \\
\text { Tinnitus }\end{array}$ & $\begin{array}{c}56 \\
13 \\
38 \\
40 \\
54 \\
98 \\
19 \\
9 \\
39 \\
77 \\
7 \\
11 \\
32\end{array}$ & $\begin{array}{c}52.3 \\
12.5 \\
35.5 \\
22.7 \\
30.7 \\
56.3 \\
10.8 \\
5.1 \\
22.1 \\
43.7 \\
3.9 \\
7 \\
18.8\end{array}$ & $\begin{array}{c}18 \\
6 \\
13 \\
18 \\
16 \\
36 \\
9 \\
4 \\
15 \\
40 \\
6 \\
1 \\
13\end{array}$ & $\begin{array}{c}48.6 \\
16.2 \\
35.1 \\
24 \\
21.3 \\
48 \\
12 \\
5.3 \\
20 \\
53 \\
8 \\
1.5 \\
17.6\end{array}$ & $\begin{array}{c}38 \\
7 \\
25 \\
22 \\
38 \\
62 \\
10 \\
5 \\
24 \\
37 \\
1 \\
10 \\
19\end{array}$ & $\begin{array}{c}54.3 \\
10 \\
35.7 \\
21.8 \\
37.6^{*} \\
62.6 \\
9.9 \\
4.9 \\
23.7 \\
37 \\
1^{*} \\
10.8^{*} \\
19.8\end{array}$ \\
\hline
\end{tabular}

the univariate analysis, frequencies and percentages were reported for categorical variables, and measures of central tendency and variability were calculated for continuous variables. For the bivariate analysis, mean differences and proportions were tested with Student's t-test and with chi-square or Fisher's exact test, respectively. Variability in the hearing thresholds of the population was evaluated with multiple linear regression models. A p-value $<0.05$ was considered statistically significant in all tests.

\section{Ethical aspects}

All participants signed an informed consent letter before study enrollment. The research project complied with the principles of the Declaration of Helsinki, and was evaluated and approved by the Mexican Institute of Social Security Ethics Committee (protocol number R-2009-3601-89). In order to protect patient confidentiality, personal information was omitted and a progressive numeric identifier was used instead.

\section{Results}

One hundred and seventy-seven out of 196 participants were included, since 18 had an audiological test outside normal ranges and one participant did not complete the audiological evaluation. In the final sample, $43 \%$ were females and $57 \%$ were males, with a mean age of $30 \pm 9.39$ and $29 \pm 8.82$ years, respectively. About half the study population reported working as professionals, with a mean commuting time of $43 \pm 30.4$ minutes. On the other hand, a higher prevalence of smoking and a larger proportion of ear fullness were reported among men, who also had significantly higher systolic blood pressure; $18.8 \%$ of the population reported the presence of tinnitus (Table 1).

Regarding the hearing pattern, audiograms from both ears are presented in figure 1. Hearing thresholds ranged between -10 and $<25 \mathrm{~dB} H \mathrm{HL}$ in the range from 125 to $8000 \mathrm{~Hz}$. No statistically significant differences were found between right and left ears; 
Left ear

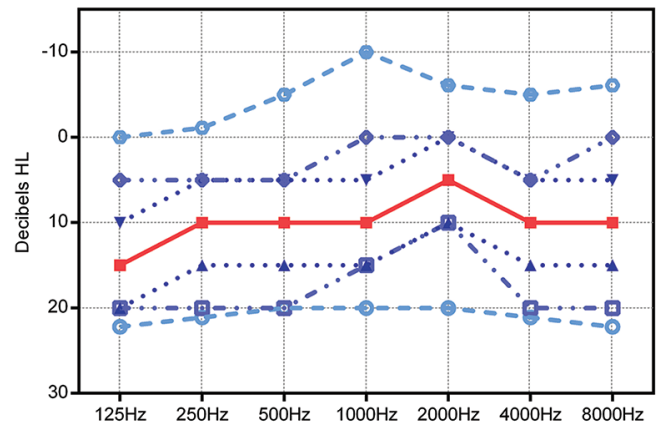

Right ear

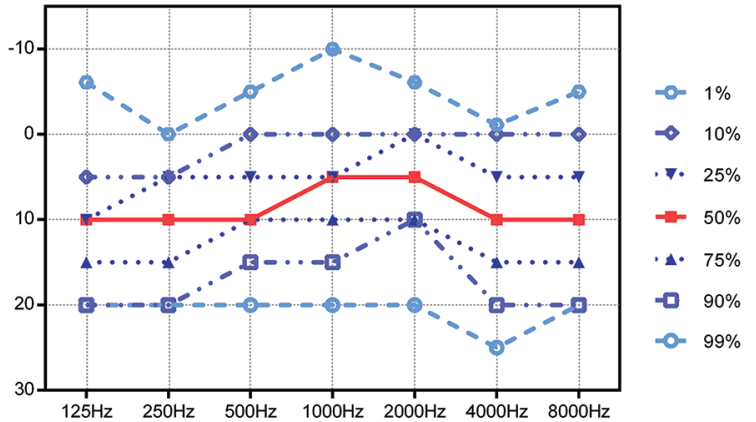

Figure 1. Distribution by percentiles of both ears' hearing thresholds in a sample of healthy adults, Mexico City $(n=177)$. Hearing patterns ranged within normal values (<25 dB HL).

Left ear

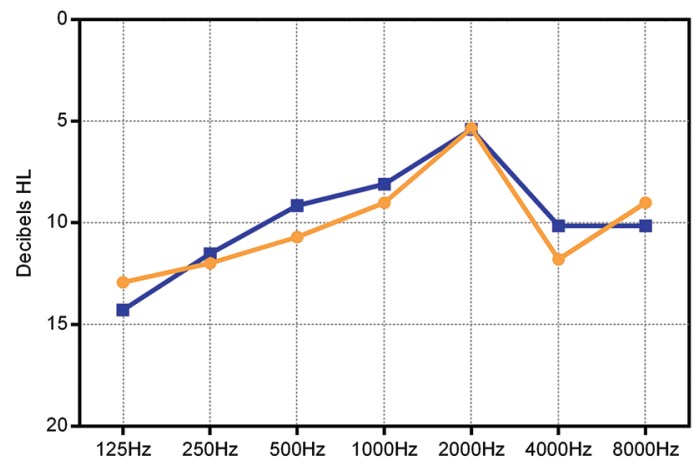

Right ear

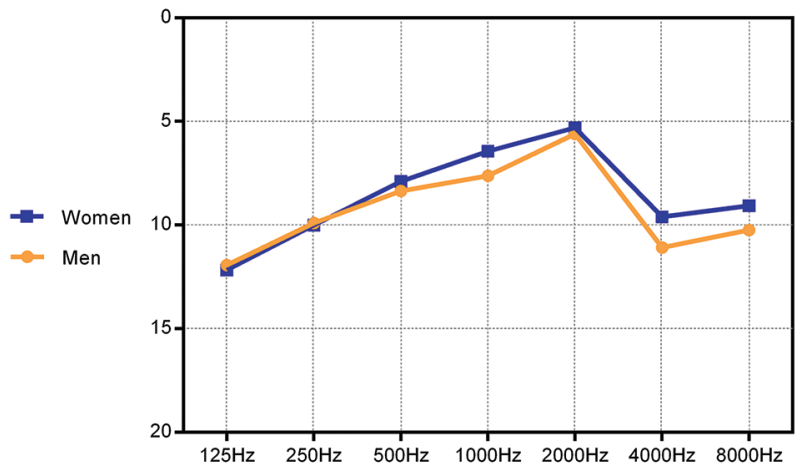

Figure 2. Mean hearing thresholds of both ears by gender in a sample of healthy adults, Mexico City $(n=177)$.

Left ear

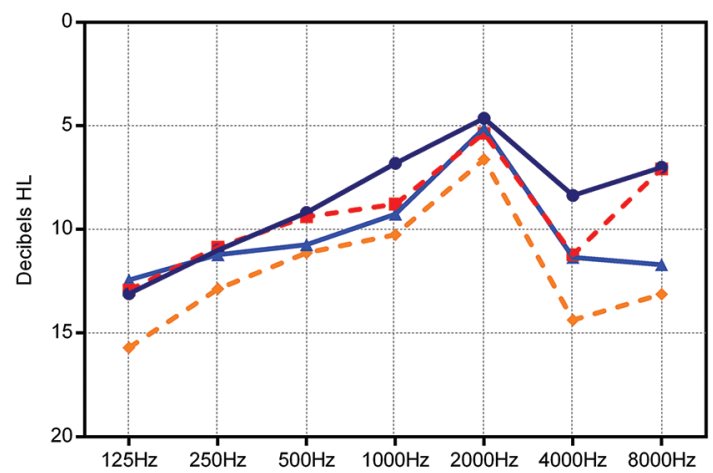

Right ear

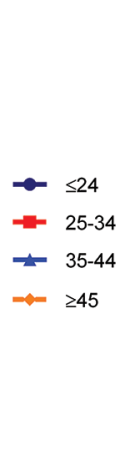

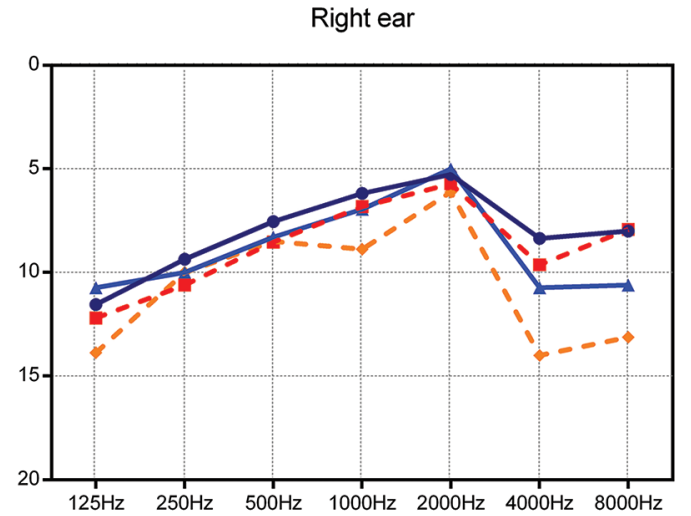

Figure 3. Mean hearing thresholds of both ears by age groups (years) in healthy adults, Mexico City $(n=177)$. Hearing thresholds increased with age (from 35 years of age on), especially at 4000 and $8000 \mathrm{~Hz}$.

however, a hearing pattern characterized by a drop starting at $4000 \mathrm{~Hz}$ and a recovery at $8000 \mathrm{~Hz}$ was observed, although these values were within normal limits $(<25 \mathrm{~dB} \mathrm{HL})$ (Fig. 1). The same pattern was observed in subsequent analyses by age and gender. Although no significant differences were found in the aforementioned frequencies, women exhibited better hearing thresholds in almost all frequencies compared 
Table 2. Robust linear regression model of hearing threshold at $4000 \mathrm{~Hz}^{*}$ in a sample of healthy adults from Mexico City, 2009-2011 ( $n=149)$

\begin{tabular}{l|c|c|c|c|}
\hline Variables & $\beta$-coefficient & $95 \%$ Cl & Standard error & $p$ \\
\hline $\begin{array}{l}\text { Age (years) } \\
25-34\end{array}$ & 2.2 & $-0.2,4.6$ & 1.22 & 0.07 \\
$35-44$ & 5.2 & $2.9,8.2$ & 1.53 & 0.001 \\
\hline $45-61$ & 8.3 & $4.7,11.8$ & 1.80 & $<0.001$ \\
\hline Males & 2.6 & $0.6,4.5$ & 0.97 & 0.009 \\
\hline $\begin{array}{l}\text { Commuting } \\
\text { time }>40 \text { min }\end{array}$ & 2.96 & $0.9,5.02$ & 1.04 & 0.005 \\
\hline
\end{tabular}

to men, especially at $4000 \mathrm{~Hz}$ (Fig. 2). On the other hand, the analysis by age groups showed worse hearing thresholds as age increased, with statistically significant differences between participants in the groups of 35 to 44 years and $\geq 45$ years at 4000 and $8000 \mathrm{~Hz}$ in both ears $(p<0.05)$ (Fig. 3).

In addition, several linear regression models were generated in order to identify the predictors of hearing thresholds for each frequency. After excluding individuals with a history of otitis media and frequent upper respiratory tract infections, the final sample for the models included 149 participants. As it can be observed in figures 1 to 3 , the worst hearing thresholds were observed at $4000 \mathrm{~Hz}$, which is why an average of both ears was calculated for this frequency and was considered as a response variable in a robust linear regression model. The main determinants of this average bilateral hearing threshold were gender (men had a worse hearing threshold in comparison with women), commuting time longer than 40 min, and age, with a gradient of worse hearing thresholds as age increased (Table 2). Finally, sociodemographic variables, chronic diseases, use of ototoxic drugs, smoking, alcohol intake, head trauma, otologic symptoms, and biological measurements were tested, but none did significantly modify the model.

\section{Discussion}

In the present study, being male, older ages, and long commuting times were associated with a statistically significant shift in hearing thresholds in a sample of healthy Mexican adults. Although hearing thresholds in this population did not meet the criteria to be considered as hearing loss and were within normal limits, even at older ages ${ }^{13}$, the audiometric pattern resembles that of noise-induced hearing loss, characterized by a drop in hearing thresholds at 4000 and $6000 \mathrm{~Hz}$ and a recovery at $8000 \mathrm{~Hz}$, which has been identified to a larger extent in populations exposed to industrial noise ${ }^{14,15}$. In addition, the audiometric curve in subjects aged 45 years or older did not show any presbycusis pattern, as it would be expected in older adult populations, which suggests a possible role of noise in our findings (Figs. 1-3). Finally, females exhibited better hearing patterns than males, as previously reported 8 .

Although there is not a large body of evidence pointing at an association between commute times and hearing loss, big cities, such as Mexico City, share certain similarities regarding commute times and environmental noise levels, which may contribute to the discussion of our results. For example, according to the United States Census Bureau, in 2018, mean travel time to work in New York City was reported to be 41 minutes $^{16}$. On the other hand, a study conducted in that city found a hearing loss of $2.46 \mathrm{~dB} \mathrm{HL}$ at $4000 \mathrm{~Hz}$ - similar to our findings - in adult populations exposed to occupational and non-occupational sources of noise; another report estimated average environmental noise level to be $73.4 \mathrm{dBA}$ on the streets ${ }^{17,18}$. In Toronto, according to the 2016 census, the majority of the population spent an average of 33 to 44 minutes on daily commutes and the most commonly used means of transportation were private vehicles and public transport ${ }^{19}$. In that city, noise measurements carried out inside the subway, on bus and streetcar routes revealed that peak noise levels reached 100 $\mathrm{dBA}$, not continuously but in the form of intermittent bursts of noise that can affect commuters' hearing if a sufficient cumulative dose is reached ${ }^{20}$. Similarly, noise levels in Mexico City range from 55 to $85 \mathrm{dBA}$, depending on the source (higher in street markets and public transport); subway noise can reach levels between 69 and $79 \mathrm{dBA}$, with maximum peaks of 85.8 $\mathrm{dBA}$ during rush hours ${ }^{6}$. Although recommended environmental noise levels should be lower than 55 $\mathrm{dBA}^{21}$, a person who moves within México City is exposed to harmful environmental noise levels during daily commutes, which is exacerbated by long commute times.

Commute time is an important indicator beyond economic and labor relevance and has direct health implications. For example, long commute times have been associated with alterations in the perception of well-being, stress, and happiness ${ }^{22-24}$. In Selangor, Malaysia, up to $40 \%$ of surveyed commuters referred 
public transport travel times longer than one hour every day and reported associated physical fatigue, weakness, and cough ${ }^{25}$. Similarly, commuting times between 30 and 60 min were associated with poor sleep quality, daily stress, and poor health among Skåne's workforce, in Sweden ${ }^{26}$.

Although our study population did not exhibit hearing loss, tinnitus was considerably prevalent (18.8\%), which may be a prelude to incipient hearing loss. This symptom has been mainly associated with sensorineural hearing loss, ear infections, and head and neck problems ${ }^{27}$, but can be present in healthy individuals. In this sense, an investigation reported a prevalence of tinnitus of $23 \%$ in healthy young Swedish adults, who also had a higher risk of hearing loss at higher frequencies when exposure to noise was followed by the onset of tinnitus ${ }^{28}$.

Finally, the strengths and limitations of this research should be mentioned. Among the strengths, the study population attended a blood bank as donors, and their health status was therefore considered to be good. In addition, people used to repeat the same commuting patterns, and, therefore, the duration of commutes did not substantially vary. Furthermore, audiological tests were carried out by trained professionals using standardized protocols, which guarantees the reliability of measurements. On the other hand, we did not collect information on the use of headphones or earplugs, which has increased among the general population due to a wider access to mobile devices, as well as attendance at concerts or music venues. In addition, housing and neighborhood conditions were not examined either for identifying whether participants lived near sources of environmental noise.

In conclusion, according to our findings, commute times longer than $40 \mathrm{~min}$, age, and the male gender were associated with hearing threshold shifts in a sample of healthy adults from Mexico City. Furthermore, the hearing pattern in this population was within normal parameters, although it resembles that of noise-induced hearing loss, and it persisted despite gender and age differences. Commuting time is important when hearing thresholds are assessed, even if values are within normal parameters, especially in urban populations. However, environmental noise levels people are exposed to is, with no doubt, the main risk that should be addressed, and complemented with other factors such as pollutants, psychological stressors and commuting patterns, which must include frequency, duration and use of various forms of public or private transport. Therefore, future studies should jointly address the aforementioned variables in order to elucidate the mechanism by means of which commutes modify hearing thresholds.

\section{Acknowledgments}

The authors would like to thank Perla Ravelo Cortés for her work with audiological tests; as well as Amparo Gómez Morán and the administrative and technical personnel at Centro Médico Nacional Siglo XXI for their support with data collection.

\section{Funding}

This work was funded by Consejo Nacional de Ciencia y Tecnología (Conacyt) of Mexico, with grant number FOSISS-07-ST-240, which did not influence the design, data collection, analysis, interpretation or writing of this work.

\section{Conflict of interests}

The authors declare that there were no conflicts of interest.

\section{Ethical disclosures}

Protection of human and animal subjects. The authors declare that no experiments were performed on humans or animals for this study.

Confidentiality of data. The authors declare that they have followed the protocols of their work center on the publication of patient data.

Right to privacy and informed consent. The authors declare that no patient data appear in this article.

\section{References}

1. ruidocdmx.com. [Internet]. Mexico: Programa Experimentos Cívicos; 2019.

2. Instituto Nacional de Estadística y Geografía. Mexico: Consulta Interactiva de Datos; 2019.

3. Procuraduría Ambiental y del Ordenamiento Territorial de la Ciudad de México. Mexico: Capítulo 2. La Zona Metropolitana del Valle de México; 2019

4. Instituto Nacional de Estadística y Geografía. Mexico: Comunicado de Prensa Núm; 2019.

5. Cohen MA, Castillo OS. Noise in the city. Acoustic pollution and the walkable city. Estud Demogr Urbanos Col Mex. 2017;32:65-96.

6. Procuraduría Ambiental y del Ordenamiento Territorial del Distrito Federal. Mexico: Ruido en el Distrito Federal. Elementos Básicos; 2014.

7. IHME, Institute for Health Metrics and Evaluation/Global Burden of Disease. GBD Compare|Viz Hub; 2019.

8. Aguilar-Madrid G, Torres-Valenzuela A, Hinojos-Escobar W, CabeIlo-López A, Gopar-Nieto R, Ravelo-Cortés PE, et al. Brainstem auditory evoked potentials latencies, by age and sex, among mexican adult population. Rev Med Inst Mex Seguro Soc. 2016;54:203-110.

9. American National Standards Institute. ANSI S3.6-1996 American National Standard Specification for Audiometers. United States: American National Standards Institute; 2005.

10. American National Standards ANSI S3.1-2008 Maximum Permissible Ambient Noise Levels for Audiometric Test Rooms. United States: American National Standards Institute; 2008 
11. Daszenies SC, Lizana RM, Cofré ON. Validación de la audiometría de vía aérea (AVA) como instrumento de evaluación de hipoacusia en el adulto en atención primaria de salud. Rev Otorrinolaringol Cir Cabeza Cuello. 2005;65:215-20.

12. World Health Organization. Deafness and Hearing Loss. Switzerland: World Health Organization; 2020

13. International Organization for Standardization. International Standard ISO 7029. Switzerland: International Organization for Standardization 2000.

14. Becerril-Ramírez PB, González-Sánchez DF, Gómez-García A, Figueroa-Moreno R, Bravo-Escobar GA, de la Cruz MA. Pruebas de despistaje auditivo en adultos. Acta Otorrinolaringol Esp. 2013;64:184-90.

15. Sliwinska-Kowalska M. Hearing. In: Lotti M, Bleecker ML, editors. Handbook of Clinical Neurology. The Netherlands: Elsevier; 2015.

16. United States Census Bureau. Mean Travel Time to Work (Minutes), Workers Age 16 Years United States, New York: United States Census Bureau; 2020.

17. Lewis RC, Gershon RR, Neitzel RL. Estimation of permanent noise-induced hearing loss in an urban setting. Environ Sci Technol. 2013;47:6393-9.

18. McAlexander TP, Gershon RR, Neitzel RL. Street-level noise in an urban setting: assessment and contribution to personal exposure. Environ Health. $2015 ; 14: 18$

19. Statistics Canada. Canada: census Profile, 2016 Census. Toronto, City (Census Subdivision), Ontario and Canada (Country); 2020.
20. Yao CM, Ma AK, Cushing SL, Lin VY. Noise exposure while commuting in Toronto a study of personal and public transportation in Toronto. J Otolaryngol Head Neck Surg. 2017;46:1-8.

21. World Health Organization [Internet]. Denmark: Noise Guidelines for the European Region; 2019.

22. Morris EA, Zhou Y. Are long commutes short on benefits? Commute duration and various manifestations of well-being. Travel Behav Soc. 2018;11:101-10

23. Zhu J, Fan Y. Commute happiness in Xi'an, China: effects of commute mode, duration, and frequency. Travel Behav Soc. 2018;11:43-51.

24. Giménez-Nadal JI, Molina JA. Daily feelings of US workers and commuting time. J Transp Health. 2019:12:21-33.

25. Wong LP, Alias H, Aghamohammadi N, Sulaiman NM, Lin H, Zhao J. Commuting on public transport: health risks and responses. In: del Real-Olvera J, editor. Air Pollution: monitoring, Quantification and Removal of Gases and Particles. United States: InTech Open; 2018.

26. Hansson E, Mattisson K, Björk J, Stergren PO, Jakobsson K. Relationship between commuting and health outcomes in a cross-sectional population survey in Southern Sweden. BMC Public Health. 2011:11:1-14.

27. Stohler NA, Reinau D, Jick SS, Bodmer D, Meier CR. A study on the epidemiology of tinnitus in the United Kingdom. Clin Epidemiol. 2019;11:855-71

28. Muhr P, Rosenhall U. Self-assessed auditory symptoms, noise exposure, and measured auditory function among healthy young Swedish men. Int J Audiol. 2010:49:317-25. 